\title{
VARIATIONS IN THE ORIGIN OF ARTERY TO ATRIOVENTRICULAR
} NODE

\author{
Vidyashambhava Pare ${ }^{* 1}$, Roopa Kulkarni ${ }^{2}$.
}

${ }^{* 1}$ Professor and Head, Department of Anatomy, K.V.G. Medical College and Hospital, Kurunjibagh, SULLIA - Dakshina Kannada, Karnataka, India.

${ }^{2}$ Principal and Professor of Anatomy, K.V.G. Medical College and Hospital, Kurunjibagh, SULLIA Dakshina Kannada, Karnataka, India.

\section{ABSTRACT}

Introduction: The normal functioning of the conduction system of heart is important and has increased interest in understanding their disorders. The arteries supplying the atrioventricular node have presented variations in origin. This node is supplied mainly by the branches of right coronary artery and in small number of cases it is supplied by the branches of left coronary artery. The branches of right coronary artery are broadly classified into atrial, ventricular and septal branches. The arterial supply to atrioventricular node is by the first posterior septal branch of the right coronary artery in about $80 \%$ of cases. There are inconstant branches of circumflex artery and this artery itself may terminate by supplying the $A \mathrm{~V}$ node.

Materials and Methods: Sixty human hearts were studied in the Department of Anatomy, Mysore Medical College, Mysore, for two years. They were studied by dissection method (37 hearts), corrosion cast (16 hearts), and arteriography (7 hearts).

Observation: The origin of atrioventricular nodal artery was from an atrial branch of right coronary artery in 06 specimens, ventricular branch of right coronary artery in 02 cases and interventricular septal artery in 04 cases. The atrioventricular nodal artery was seen as a terminal branch of parent artery in 07 cases. In the remaining the atrioventricular nodal artery originated from the coronary arteries directly.

Discussion: The coronary arteries develop in situ and later get connected with the aortic buds. The functional period of the embryo often determines the course of the blood flow and secondary changes. The arteries thus developed, pursue the shortest course to reach their destination. This explains for all known coronary artery anomalies. In the present study, in nineteen cases, the origin was from the atrial, ventricular or septal branches of the right or left coronary artery. Our observations coincided with the observations mentioned in Gray's anatomy partially.

Conclusion: The atrioventricular nodal artery is the nourishing channel for the atrioventricular node. The variations in the origin of atrioventricular nodal artery from, atrial, ventricular and interventricular septal arteries of right coronary artery are seen in about 19 cases. In the rest, it originated from the trunk of the coronary artery directly. This information would kindle the interest of researchers to further explore the variations in the origin of the atrioventricular nodal artery as there were no other references available.

KEY WORDS: Atrioventricular Nodal Artery, Right Coronary Artery, Left Circumflex Artery, Atrial Branches, Interventricular Septal Branches.

Address for Correspondence: Dr. V.S. Pare, Professor \& Head of the Department of Anatomy, K.V.G. Medical College \& Hospital, Sullia, D.K., Karnataka, India. Mobile: 9448460498, 9901730398. E-Mail:vs_pare@yahoo.co.in

\begin{tabular}{|l|l|}
\hline \multicolumn{3}{|c|}{ Access this Article online } \\
\hline Quick Response code & Web site: International Journal of Anatomy and Research \\
ISSN 2321-4287 \\
www.ijmhr.org/ijar.htm \\
\cline { 2 - 3 }
\end{tabular}




\section{INTRODUCTION}

The anatomy of coronary arteries aroused the curiosity of Vieussens about 350 years ago, but, increase in death rate due to heart diseases and diseases of the coronary arteries and chest pain alarmed the research workers to dive in to the depth, to know the gross anatomical details of coronary arteries of human heart.

The development of open heart surgery encouraged the scientists to work more on the normal and anatomical variations of the branches of coronary arteries, the collateral circulation and its importance.

The conduction system of heart and its normal functioning is of utmost importance and increased interest in the disorders of sino atrial node and atrioventricular node together with known vulnerability of the nodes to surgical injury have reawakened the thirst for knowledge of its anatomy, histology, age changes and vascular supply [1].

The arteries supplying the atrioventricular node presented variations in the origin. It was stated that the left coronary artery is preponderant in virtually all normal hearts [2]. But in most of the hearts atrioventricular nodal arterial supply was by right coronary artery.

Hutchinson MCE studied atrial arteries in humans, considering the arterial supplies of sinoatrial and atrioventricular nodes in detail. He stated that in more than half of the cases, these nodes are supplied by the branches of right coronary artery and only in small number of cases these nodes are supplied by the branches of left coronary artery. In the remaining specimens, the sinoatrial node was supplied by right coronary artery and the atrioventricular node by the other in either combination [3].

The branches of right coronary artery are broadly classified into atrial, ventricular and septal arteries. The atrial branches are further grouped into anterior, lateral and posterior arteries. The arterial supply of atrioventricular node is by the posterior septal branch of the right coronary artery in about $80 \%$ of cases. The circumflex artery, branch of left coronary artery, gives out branches which are inconstant. But the terminal branch of left circumflex artery, supplies atrioventricular node in about $20 \%$ of cases [4].
It is due to these variations, the present study has been taken up.

\section{MATERIALS AND METHODS}

Sixty human hearts were collected from the Department of Anatomy, Mysore Medical College, Mysore, from 1983 to 1985. The age and sex of each case were noted. Age varied from few months to 75 years. There were 31 hearts belonging to males and 29 hearts belonging to females. The cause of death was not known. The hearts were washed thoroughly to remove clots by using saline and $40 \%$ Borax solution. The coronary ostia in the ascending aorta were identified and carefully dissected.

Out of the sixty hearts, 37 hearts were studied by meticulous dissection method after embalming in formalin. 16 hearts were studied by preparing corrosion casts using butyl butyrate and 07 hearts were studied radiographically (arteriography) by injecting radio opaque material, which consisted of finely triturated $20 \%$ aqueous solution of red lead (15 gm \%) and starch (5gm \%), into the coronary arterial system. These 07 hearts were embalmed in 10\% formalin and preserved in $07 \%$ formalin solution.

\section{OBSERVATION AND RESULTS}

The artery to atrioventricular node was visualized and the parent artery was noted. The observations were tabulated depending upon the source of the artery to atrioventricular node.

In the remaining specimens the main coronary artery was the source of the artery to atrioventricular node.

Fig. 1: Origin of atrioventricular nodal artery from Posterior right atrial artery, branch of right coronary artery.

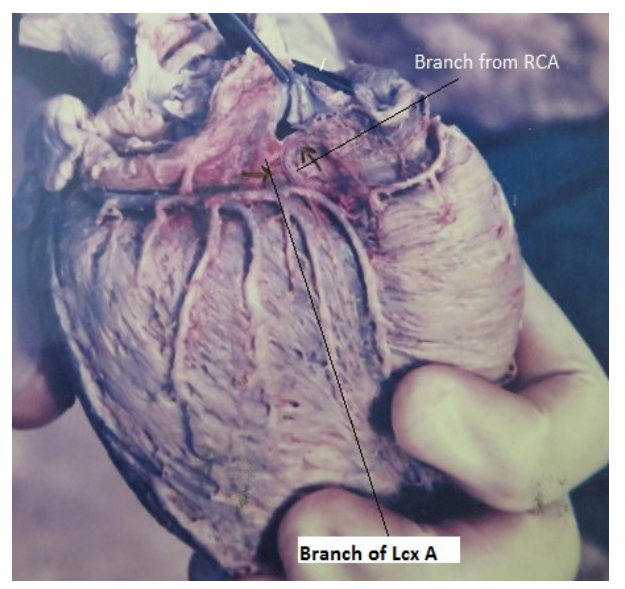

RCA=Right Coronary Artery, LcxA = Left Circumflex Artery, 
Vidyashambhava Pare, Roopa Kulkarni. VARIATIONS IN THE ORIGIN OF ARTERY TO ATRIOVENTRICULAR NODE.

Table 1: Showing variation in the origin of artery to atrioventricular node in 19 cases.

\begin{tabular}{|c|c|c|c|c|c|c|c|}
\hline \multirow[t]{2}{*}{ S.No. } & \multicolumn{3}{|c|}{ From Atrial artery } & \multicolumn{2}{|c|}{ From ventricular artery } & \multirow{2}{*}{$\begin{array}{c}\text { From } \\
\text { interventricular } \\
\text { septal artery }\end{array}$} & \multirow{2}{*}{$\begin{array}{l}\text { Termination of parent } \\
\text { artery as A-V nodal } \\
\text { artery }\end{array}$} \\
\hline & $\begin{array}{l}\text { Posterior Rt. } \\
\text { Atrial artery }\end{array}$ & $\begin{array}{l}\text { Posterior Lt. } \\
\text { atrial artery }\end{array}$ & $\begin{array}{l}\text { Lateral right } \\
\text { atrial artery }\end{array}$ & $\begin{array}{c}\text { Posterior. Inter- } \\
\text { ventricular } \\
\text { artery }\end{array}$ & $\begin{array}{c}\text { Posterior Left } \\
\text { ventricular } \\
\text { artery }\end{array}$ & & \\
\hline 1 & 2 & 3 & 1 & 2 & - & 4 & 7 \\
\hline Total & \multicolumn{3}{|c|}{6} & \multicolumn{2}{|c|}{2} & 4 & 7 \\
\hline$\%$ & \multicolumn{3}{|c|}{$10 \%$} & \multicolumn{2}{|c|}{$3.33 \%$} & $6.66 \%$ & $11.66 \%$ \\
\hline
\end{tabular}

Fig. 2: Origin of atrioventricular nodal artery from Posterior left atrial artery branch of right coronary artery. $(\mathrm{RCA}=$ right coronary Artery).

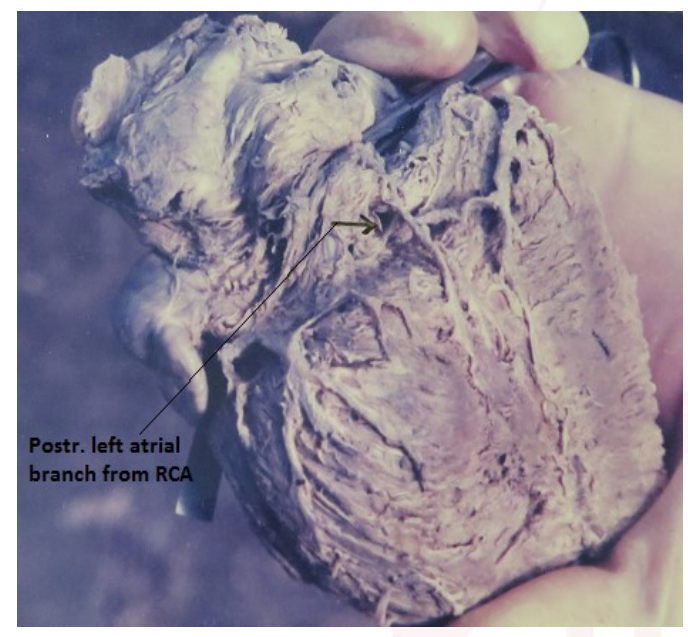

Fig. 3: Origin of atrioventricular nodal artery as a branch of Posterior inter-ventricular artery.

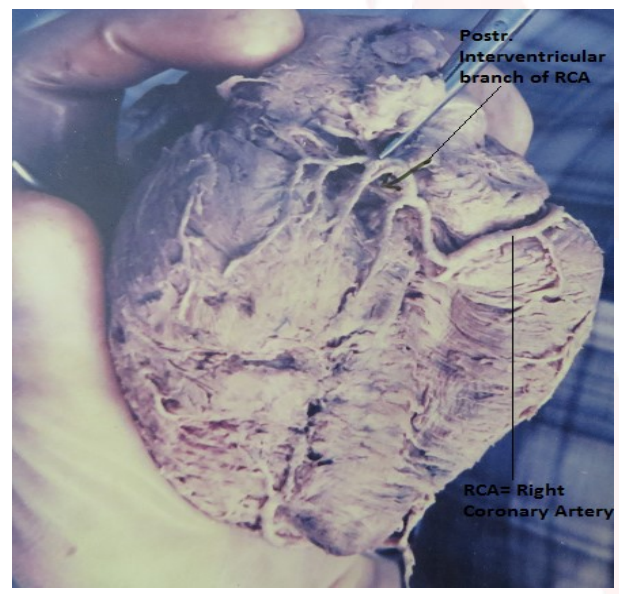

Fig. 4: Origin of atrioventricular nodal artery from interventricular septal artery.

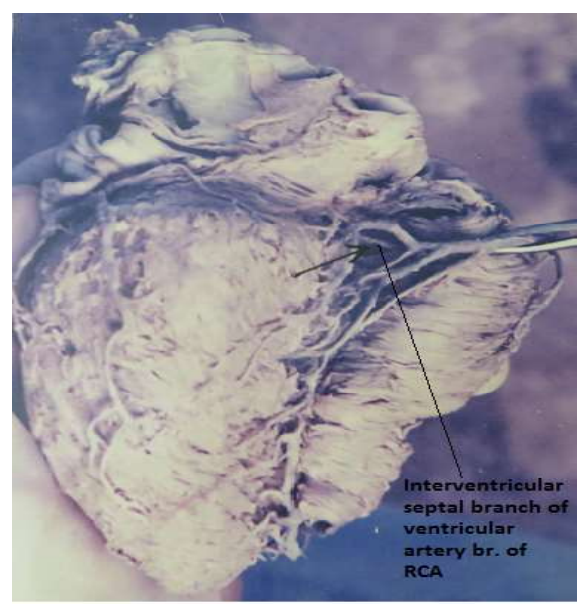

Fig. 5: Termination of parent artery (RCA= Right Coronary Artery) as atrioventricular nodal artery. A branch from Left circumflex artery is also present forming dual supply. (Arrows).

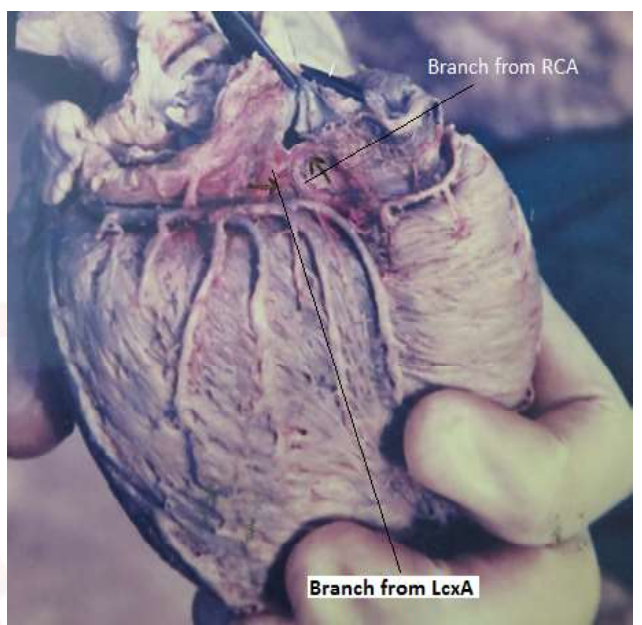

RCA=Right Coronary Artery, LcxA = Left Circumflex Artery,

\section{DISCUSSION}

An extensive knowledge of anatomy of the coronary arteries, arterial supply of the sinoatrial node and atrioventricular node of the heart is a self-evident pre-requisite for the intelligent planning of surgery.

The blood vessels develop prior to the establishment of circulation, the initial phase of nourishment and drainage of the predominantly spongy wall of the heart, being by the inter-trabecular spaces or sinusoids. The coronary arteries develop in situ and later get connected with the aortic buds. The functional period of the embryo often determines the course of the blood flow and secondary changes, both structurally and functionally, are established. Oxygen, typical endothelio-mesenchymal inductive interactions play a great role in the development of blood vessels, the outcome being the resultant of the heredity and environmental effects on the developing embryo. The developed arteries, in general, pursue the shortest and most direct course so as to reach their areas of supply. Once they are established, they retain their pathway, as seen in various organs. 
Therefore the mode of development of the coronary arteries and their branches gives an explanation for all known coronary artery anomalies [5-8].

Normally the atrioventricular nodal artery arises from right coronary artery. It was given off at or near the crux in about $84 \%$ of cases [9]. The atrioventricular nodal artery originated from both right coronary artery and left circumflex artery in $07 \%$ of cases. The atrioventricular nodal artery originated from left circumflex artery in 09\% of cases. These values almost coincided with other authors $[2,3,8]$. In another observation, the atrioventricular nodal artery was found to be the first and the longest inferior septal perforating branch of, right coronary artery in about $90 \%$ of cases or left coronary artery in $10 \%$ of cases. Usually it arises from the ' $U$ ' or ' $V$ ' shaped segment of the corresponding artery at the crux [10].

In the present study, in nineteen cases, the origin was from the atrial, ventricular and septal branches of the right or left coronary arteries. (Table 1). In 02 cases it originated from posterior right atrial branch which was an atrial branch of right coronary artery (Figure 1). In 03 cases the atrioventricular nodal artery originated, one each, from posterior left atrial branch of right coronary artery (Figure 2), both right coronary artery and left circumflex artery. In one specimen, the artery was seen arising from lateral right atrial artery a branch of right coronary artery and in the other only left circumflex branch of left coronary artery. The last two arteries were very small and fragile and photographs could not be taken. In 02 cases the atrioventricular nodal artery originated from the posterior interventricular branch of right coronary artery (Figure 3). The other site of origin of atrioventricular nodal artery, in 04 cases, was from interventricular septal branch of right coronary artery (Figure 4). Termination of the parent trunk as atrioventricular nodal artery was found in 07 cases. (Figure 5). Our observations coincided with the observations mentioned in Gray's anatomy, but there was no other reference available for the specific branch of right coronary artery or left coronary artery.

\section{CONCLUSION}

The atrioventricular nodal artery is the main nourishing channel for the atrioventricular node of the conducting system of heart. The variations in origin of atrioventricular nodal artery from atrial, ventricular and interventricular septal arteries of right coronary artery, were noted. The atrial branches are further grouped into anterior, lateral and posterior arteries. The arterial supply of atrioventricular node is by the posterior septal branch of the right coronary artery in about $80 \%$ of cases. The circumflex artery, branch of left coronary artery gives out branches which are inconstant. In the present study there were variations seen in about 19 cases, in which the atrioventricular nodal artery originated from, posterior right atrial, posterior left atrial, lateral atrial branches, posterior interventricular and interventricular septal branches of right coronary artery. In the remaining specimens, the atrioventricular nodal artery originated from the trunk of the coronary arteries directly. This information would kindle the interest of researchers to further explore the variations in the origin of the atrioventricular nodal artery as there were no other references available.

\section{Conflicts of Interests: None}

\section{REFERENCES}

[1]. R.H. Anderson, S.Y.Ho and A.E. Becker, The surgical anatomy of the conduction tissues. Thorax. 1983, June;38(6):408-420.

[2]. James T.N., Anatomy of Coronary arteries in Health and disease. Circulation, 1965;32:1020-1033.

[3]. Hutchinson M.C.E., A Study of Atrial Arteries in Man; Journal of Anatomy; 1978;125:39-54.

[4]. Susan Standring; Gray's Anatomy, Ch. Thorax, Section 7; chapter 56, Heart and great vessels. 2008, $40^{\text {th }}$ edition. Elsevier Churchill Livingstone. Page no. 977-981.

[5]. David E. Reese, Takashi Mikawa and David M. Bader; Development of Coronary Vessel System. Circulation Research; 2002;91:761-768.

[6]. Adriana DM Villa, Eva Sammut, Arjun Nair, Ronak Rajani, Rodolfo Bonmini and Amedeo Chiribiri, Coronary artery anomalies overview: The normal and the abnormal. World J. Radiol. 2016 June 28;8(6):537-555

[7]. PITT, B. Interarterial coronary anastomoses. Occurance in normal hearts and in certain pathologic conditions. Circulation, 1959, Nov. 20;81622.

[8]. Baroldi G, Mantero O, Scomazzoni G. The collaterals of the coronary arteries in normal and pathologic heart. Circulation Research. 1956;4:223-9. 
[9]. Anderson and Becker, Cardiac anatomy - An integrated Text and Colour Atlas. London: Gower Medical Pub.; Edinburgh; New York: Churchill Livingstone, 1980.
[10]. Pejkovic B, Krajnc I, Anderhuber F, Kosutic D., Anatomical aspects of the arterial blood supply to the sinoatrial and atrioventricular nodes of the human heart. J. Int. Med. Res. 2008, July- Aug;36(4):691-8.

How to cite this article:

Vidyashambhava Pare, Roopa Kulkarni. VARIATIONS IN THE ORIGIN OF ARTERY TO ATRIOVENTRICULAR NODE. Int J Anat Res 2017;5(3.2):4182-4186. DOI: 10.16965/ijar.2017.280 